\title{
Effects of dormant duration, body size, self-burial and water condition on the long-term survival of the apple snail, Pomacea canaliculata (Gastropoda: Ampullariidae)
}

\author{
Yoichi YuSA, ${ }^{1,2, *}$ Takashi WADA ${ }^{1}$ and Satoshi TAKAHASHI ${ }^{2}$ \\ ${ }^{1}$ National Agricultural Research Center for Kyushu Okinawa Region (KONARC); Nishigoshi 861-1192, Japan \\ ${ }^{2}$ Faculty of Science, Nara Women's University; Nara 630-8506, Japan \\ (Received 10 December 2005; Accepted 6 July 2006)
}

\begin{abstract}
We investigated factors influencing the survival of the apple snail, Pomacea canaliculata during dormancy in the laboratory at $20-26^{\circ} \mathrm{C}$. We placed snails of three size classes in small pots with soil and water, drained the water to induce self-burial, and subsequently checked the snails' survival at intervals. The duration of the dormant period, body size and the success of self-burial all affected the survival of the snails. The effects of water conditions (dry or moist) affected the survival of the snails through interactions with body size and duration. The longest duration of survival under dry conditions was 11 months, and a small proportion of medium-sized and large snails survived the entire experimental period of 29 months under moist conditions.
\end{abstract}

Key words: Estivation; freshwater snail; invasive species; mortality; rice pest

\section{INTRODUCTION}

The apple snail, Pomacea canaliculata (Lamarck) (Gastropoda: Ampullariidae) is the only species among freshwater snails which is ranked in the top 100 of the world's worst invasive alien species (Lowe et al., 2000), and is also included in a similar list in Japan (The Ecological Society of Japan, 2002). It originates from South America, but has been introduced into many tropical, subtropical, and temperate Asian and American countries (Lach et al., 2000; Cowie, 2002). In paddy fields, attacks on rice seedlings are severe when paddy water is deep (Shobu, 1996; Wada, 1997), and farmers are often forced to spray pesticides or conduct other labor-intensive control methods, including hand-picking. However, none are effective enough to prevent snails from feeding on rice during the rainy season. In addition, the apple snail has a severe ecological impact by changing the structure of local ecosystems by eradicating most vegetation (Carlsson et al., 2004).

One reason why $P$. canaliculata is successful as an invasive species is its ability to survive in vari- ous environments (Lach et al., 2000); P. canaliculata can endure harsh environmental circumstances by burying itself in the soil and closing its operculum firmly (Cowie, 2002). In fact, unfavorable circumstances such as low water levels, extreme temperatures or lack of food are known to induce selfburial in this species (Wada and Yoshida, 2000).

Among various environmental stresses, the ability of ampullariid snails to endure dryness has attracted the interest of many scientists (reviewed in Cowie, 2002). Ampullariids generally inhabit temporary water bodies in tropical or sub-tropical areas, bury themselves in soil and rest during the dry season (Burky et al., 1972) (hereafter referred to as "dormancy" to include both estivation and hibernation). In Pomacea snails, factors such as duration (Little, 1968; Burky et al., 1972; Fan et al., 2000; Darby et al., 2003), water conditions (Darby et al., 2003), or the body size of snails (Fan et al., 2000; Darby et al., 2003) are known to affect survival during dormancy; however, no studies have investigated all these effects in detail in a single species. As mortality during dormancy is important to understand the success of $P$. canaliculata as

* To whom correspondence should be addressed at: E-mail: yusa@cc.nara-wu.ac.jp DOI: $10.1303 / \mathrm{aez} .2006 .627$ 
an invasive species, an extensive study incorporating these factors is needed.

Recently, Wada et al. (2004) reported that the density of $P$. canaliculata in June after one season of crop rotation with upland crops (soybean) was less than $1 / 10$ of the density in fields after rice. Crop rotation is a practical way to reduce the snail population without using pesticides or other laborintensive control methods; however, the mechanisms by which snail density is reduced are not fully understood (dryness, tillage, and/or extreme temperatures?). The effects of low temperatures (Ozawa and Makino, 1988; Watanabe et al., 2000; Shobu et al., 2001) or tillage (Takahashi et al., 2000, 2005) have been studied extensively. In the case of dryness, all previous laboratory studies in $P$. canaliculata were conducted under dry conditions, with no water given during experiments. It is unknown how long snails survive if water is given regularly to simulate rainfall. The purpose of this study was to investigate the effects of various factors on the survival of $P$. canaliculata during dormant periods.

\section{MATERIALS AND METHODS}

Collection and preparation of snails. Pomacea canaliculata were collected in mid-September 2002 from paddy fields and adjacent drainage canals in Shichijo Town, Kumamoto Prefecture, Kyushu, Japan $\left(32^{\circ} 57^{\prime} \mathrm{N}\right.$; $\left.130^{\circ} 45^{\prime} \mathrm{E}\right)$; the paddy fields were about to be drained for harvesting. The snails were categorized as "small" (range: $8 \pm 1$ $\mathrm{mm}$ shell height), "medium" ( $15 \pm 2 \mathrm{~mm})$ or "large" $(30 \pm 3 \mathrm{~mm})$. Only large snails exceeded the body size at sexual maturity (ca. $25 \mathrm{~mm}$; Tanaka et al., 1999; Cowie, 2002). We did not use snails of other sizes.

In the laboratory, we reared the snails in four $60 l$ tanks for 1-7 d. A vegetable ("Komatsuna"; Brassica campestris) was given as food $1 \mathrm{~d}$ before the experiment to keep them active, but no food was given during the experiment. We marked the shells of snails with colored paint according to their size. No apparent effect of painting was observed.

Experimental procedure. We conducted the entire experiment in the laboratory at temperatures of $20-26^{\circ} \mathrm{C}$ and $14 \mathrm{~L}: 10 \mathrm{D}$ light conditions, with additional natural light through a small window. We prepared 100 Wagner's pots (round pots with a sur- face area of $1 / 5,000 \mathrm{a}$, or $200 \mathrm{~cm}^{2}$ ) with a hole near the bottom for draining. A $5 \mathrm{~cm}$ layer of soil (from paddy fields at KONARC) was used, with $5 \mathrm{~cm}$ water above the soil surface. Subsequently, we placed 10 small and 10 medium snails into each of 50 pots, and 10 large snails into each of the remaining 50 pots ( $n=500$ snails for each size class). We covered the top of each pot with mesh to prevent snails from escaping. The next day, we lowered the water level to just cover the soil surface, to allow the snails to bury themselves in the soil. Shallow water levels are known to induce burial behavior in $P$. canaliculata (Wada and Yoshida, 2000). This water level was maintained for $1 \mathrm{~d}$, after which the water was allowed to drain through the hole plugged with cotton (to drain the water slowly without losing soil). Some snails were moving a few days after draining, but subsequently no snails were found moving, even during watering periods (see below).

Two weeks later, the number of snails on the soil surface was counted. Snails were defined as at the "surface" when at least half of the shell was above the soil surface in each pot. Other snails were categorized as "buried." During the 29-month experimental period, the soil hardened and reduced in volume, and many snails which had not been on the surface became exposed; however, whether snails were on the surface or buried was categorized based on their initial conditions.

Snails in pots were treated with two water conditions: (i) The "dry" condition meant that snails were not given any water during the entire experimental period; (ii) the "moist" condition meant that ample water was given using a shower so that the soil surface was completely covered with water, two or three times a month. The soil surface before showering was not completely dry. Therefore, there were four different treatments for experimental pots (dry or moist conditions to small + medium or large snails). For each treatment, the survival of snails was observed at intervals: 0.5 ("moist" only, when the soil was not completely dry), 1, 2, 4, 7, $11,16,22$ and 29 months after the start of the experiment. For each observation, surface and buried snails were collected separately, and their survival was checked by placing them in water. Those showing no activity for $1 \mathrm{~d}$ had their responses checked by pressing the operculum to assess if they displayed any retracting behavior. Three pots were 
Table 1. Summary of a generalized linear model with the minimum AIC value concerning the effects of various factors on the survival of Pomacea canaliculata during dormancy

\begin{tabular}{lrrrr}
\hline \multicolumn{1}{c}{ Parameters } & Estimate & $S E$ & $z$ & $p$ \\
\hline Intercept & 5.40 & 0.62 & 8.68 & $<0.001$ \\
Duration & -0.97 & 0.12 & -8.17 & $<0.001$ \\
(Duration) & 0.03 & 0.01 & 4.84 & $<0.001$ \\
(Duration) & -0.00001 & 0.000004 & -3.67 & $<0.001$ \\
Size (medium) & 0.17 & 0.95 & 0.18 & 0.86 \\
Size (small) & 3.61 & 1.83 & 1.97 & $<0.05$ \\
Self-burial & -3.96 & 0.45 & -8.72 & $<0.001$ \\
Water condition & 0.88 & 0.49 & 1.81 & 0.07 \\
Duration $\times$ Water condition & 0.12 & 0.07 & 1.80 & 0.07 \\
Size (medium) $\times$ Self-burial & 3.81 & 0.86 & 4.41 & $<0.001$ \\
Size $($ small) $\times$ Self-burial & 4.64 & 0.77 & 6.00 & $<0.001$ \\
Size $($ medium) $\times$ Water condition & 0.48 & 1.13 & 0.42 & 0.67 \\
Size $($ small) $\times$ Water condition & -3.84 & 1.91 & -2.02 & $<0.05$ \\
Duration $\times$ Size $($ medium) & -0.32 & 0.17 & -1.89 & 0.06 \\
Duration $\times$ Size (small) & -2.30 & 0.62 & -3.70 & $<0.001$ \\
Duration $\times$ Water condition $\times$ Size (medium) & 0.29 & 0.17 & 1.66 & 0.10 \\
Duration $\times$ Water condition $\times$ Size (small) & 2.13 & 0.62 & 3.42 & $<0.001$ \\
\hline
\end{tabular}

used for each treatment per observation $(n=30$ snails for each size class), except for 29 months (three moist and two dry pots for small and medium individuals, and five moist pots for large snails).

Statistical analyses. We used generalized linear models (GLMs) with the logit link function and binomial errors (Wilson and Hardy, 2002). The survival of each snail was designated as the dependent variable, and duration, body size, water condition and the success of self-burial as independent variables. All tests were conducted using software R Version 2.2.1 (R Development Core Team, 2005). We started from the full model containing all the main effects and interactions (with the duration treated as polynomial up to quadric power). We then selected best-fit models using the "step" function in R, which searches for the model with the lowest value in Akaike's information criterion (AIC). In addition, we conducted the same procedures for each of the three size classes separately, including duration (up to quadric power), water condition and self-burial as the main effects and all interactions. In all best-fit models, residual deviance divided by residual df was smaller than 1 , indicating no overdispersion.

\section{RESULTS}

In the best-fit statistical model selected for the lowest AIC value, the duration, body size and selfburial all significantly affected the survival of Pomacea canaliculata during dormancy (Table 1). The main effect of the water condition was not almost significant $(p=0.07)$. The water condition significantly affected survival through second- and third-order interactions with body size and duration (Table 1). Other second-order interactions found to be significant were the interaction between duration and body size and that between body size and self-burial. These results are explored in detail.

As shown in the significant main effect of duration (Table 1), the survival of snails generally decreased with duration (Fig. 1). Under dry conditions without watering, five large individuals (out of 30 individuals; $17 \%$ ) survived up to 11 months, but no snails survived longer. Under moist conditions with showering 2-3 times per month, one medium-sized (out of 30 individuals; $3 \%$ ) and two large individuals (out of $50 ; 4 \%$ ) survived the entire experimental period of 29 months.

Survival was different among snails of different sizes (Fig. 1; Table 1); however, the response with time differed among snails of different sizes, as shown by the significant interaction between duration and size (Table 1). In particular, the longest 




Fig. 1. Changes in survival rates of Pomacea canaliculata in relation to body size and water conditions.

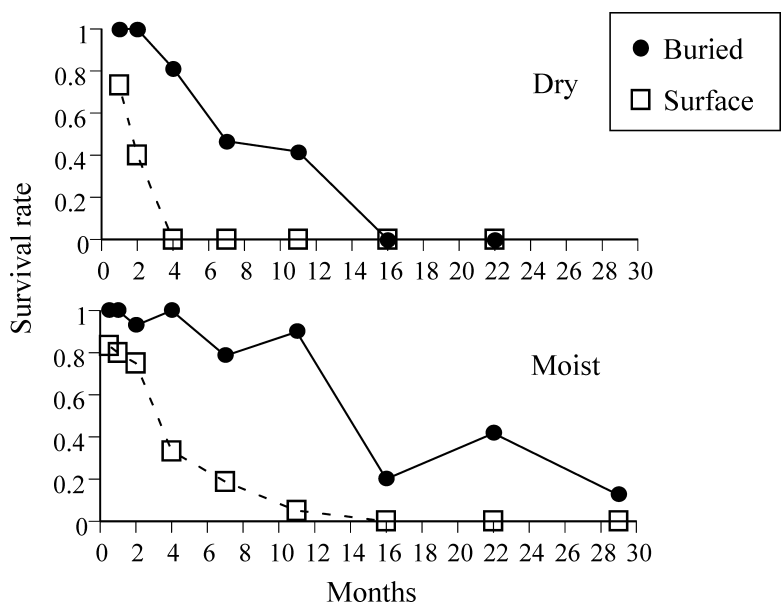

Fig. 2. Effect of self-burial on survival of large Pomacea canaliculata under dry (upper panel) or moist (lower) conditions.

survival periods under dry conditions for small, medium and large snails were 4, 7 and 11 months, respectively (Fig. 1). Survival under moist conditions was 11 months for small snails and 29 months for both medium and large snails.

The proportions of buried snails were $81 \%$ (407/500) for small snails, 95\% (475/500) for medium, and $43 \%(214 / 500)$ for large; overall, the effect of self-burial on survival was significant (Table 1). Among each size class, large snails who
Table 2. Summary of a generalized linear model with the minimum AIC value in each size class

A. Small snails

\begin{tabular}{lrrrr}
\hline \multicolumn{1}{c}{ Parameters } & Estimate & $S E$ & $z$ & $p$ \\
\hline Intercept & 8.85 & 1.72 & 5.14 & $<0.001$ \\
Duration & -3.07 & 0.61 & -5.01 & $<0.001$ \\
Water condition & -4.55 & 1.80 & -2.52 & $<0.05$ \\
Duration $\times$ Water & 2.57 & 0.62 & 4.18 & $<0.001$ \\
$\quad$ condition & & & & \\
\hline
\end{tabular}

B. Medium snails

\begin{tabular}{lrrrc}
\hline \multicolumn{1}{c}{ Parameters } & Estimate & \multicolumn{1}{c}{$S E$} & $z$ & $p$ \\
\hline Intercept & 3.25 & 0.43 & 7.58 & $<0.001$ \\
(Duration) $^{2}$ & -0.18 & 0.02 & -8.27 & $<0.001$ \\
(Duration) $^{3}$ & 0.012 & 0.002 & 8.02 & $<0.001$ \\
(Duration) $^{4}$ & -0.00023 & 0.00003 & -7.78 & $<0.001$ \\
Water condition $^{\text {Dation }}$ & 5.90 & 0.86 & 6.82 & $<0.001$ \\
\hline
\end{tabular}

C. Large snails

\begin{tabular}{lrrrr}
\hline \multicolumn{1}{c}{ Parameters } & Estimate & \multicolumn{1}{c}{$S E$} & \multicolumn{1}{c}{$z$} & $p$ \\
\hline Intercept & 5.35 & 0.67 & 7.98 & $<0.001$ \\
Duration & -0.98 & 0.17 & -5.87 & $<0.001$ \\
(Duration) $^{2}$ & 0.04 & 0.01 & 2.75 & $<0.01$ \\
(Duration) $^{3}$ & -0.0007 & 0.0003 & -2.04 & $<0.05$ \\
Self-burial & -3.92 & 0.46 & -8.50 & $<0.001$ \\
Water condition & 0.86 & 0.50 & 1.72 & 0.09 \\
Duration $\times$ Water & 0.13 & 0.07 & 1.79 & 0.07 \\
$\quad$ condition & & & & \\
\hline
\end{tabular}

buried themselves attained higher survival rates than those which failed to self-bury under both dry and moist conditions (Fig. 2; Table 2). However, the effect of self-burial was not clear for small and medium snails, indicated by the fact that this effect was not included as an explanatory variable in the best-fit models for small or medium snails (Table 2). This size-dependent effect of self-burial is expressed as the significant interaction between body size and self-burial (Table 1).

The water condition appeared to affect survival in all size classes (Fig. 1; Table 1); however, the effect was dependent on body size and duration, as shown by second- and third-order interactions among them (Table 1). In small or medium snails, the main effect of the water condition was significant in best-fit models (Table 2). In large snails, the main effect and the interaction with duration were 
almost significant (Table 2).

\section{DISCUSSION}

A small proportion of Pomacea canaliculata survived the entire experimental period of 29 months under moist conditions, which is the longest dormant period recorded in the family Ampullariidae. Cowie (2002) summarized the records of dormancy success in ampullariid snails under dry conditions, and the longest was 25 months in Pila globosa. In Pomacea snails, survival over 400 days was reported in P. lineata (Little, 1968), and most (83/126) individuals survived for 526 days in P. urceus (Burky et al., 1972). These snails would have survived much longer under moist conditions. In Pomacea canaliculata, Fan et al. (2000) reported the maximum survival periods under dry conditions to be 6 months for snails of $35-45 \mathrm{~mm}$ shell height, 10 months for $46-50 \mathrm{~mm}$ snails, and 13 months for 51-72 mm snails. Kondo and Yamaguchi (unpublished) found that snails of 30-35 mm shell height survived 25 months outdoors with changing water and temperature conditions.

In this study, no overdispersion was detected in best-fit statistical models. This suggests that the variation in the survival rate among pots was not larger than expected under binomial distribution. Thus, individuals in the same pots can be regarded as nearly independent data. Although small and medium-sized snails were put in the same pots, their performances were different. This indicates that the effects of using common pots for two different size classes were not important.

Although the main effect of the water condition did not reach a significant level, the survival of snails under dry conditions tended to be lower than that of snails under moist conditions. A similar result has been reported in the congener Pomacea paludosa (Darby et al., 2003). A lower tendency of survival under dry conditions than moist conditions suggests that water loss was the main cause of differential mortality. Although we did not monitor the weight changes of the snails, other studies reported gradual weight loss due to desiccation in dormant P. lineata (Little, 1968) and P. urceus (Burky et al., 1972).

Survival was also related to the success of selfburial, suggesting that snails who could bury themselves survived better than those who failed to bury. A possible reason is that snails in the soil were protected from desiccation and other environmental stresses; however, an alternative interpretation is possible, where snails that failed to bury were already spent and weak, and hence had difficulty in surviving. Support for this interpretation is that the relationship between self-burial and survival was detected only for large snails reaching sexual maturity (ca. $25 \mathrm{~mm}$ in shell height; Tanaka et al., 1999; Cowie, 2002), and not for small or medium snails. Most snails in paddy fields do not live for two reproductive seasons (Shobu, 1996; Wada, 1997; Watanabe et al., 2000) and hence large snails in this study may have experienced "post-reproductive die-off" (Darby et al., 2003) during dormancy. Both interpretations are probably relevant to these results, but their relative importance requires further study.

Substantial proportions of medium $(60 \%)$ and large $(17 \%)$ snails survived 22 months after the start of the experiment under moist conditions. This result illustrates the very high ability to survive during dormancy of $P$. canaliculata. On the other hand, survival in the field is much lower. Snail density after one season of crop rotation from rice to soybeans was $<1 / 10$ of that under normal circumstances (Wada et al., 2004). Considering that snail density is also reduced in normal fields, survival after crop rotation is very low (comparison between snail densities in spring and autumn indicates that spring density was $<1 / 1,000$ lower than autumn density; Wada et al., 2004). In Kyushu, Japan, the time without surface water is 20-21 months in fields with crop rotation. Thus, other factors, such as extreme temperatures or tillage, may be important to reduce snail density in these fields.

The longest period of survival in this study was 29 months, and a small proportion of snails might have survived even longer if we had continued the experiment. Thus, although snail survival may be lower in the field, rotation with upland crops for two consecutive seasons, which will result in a period without surface water of 32-33 months, might not fully eradicate all snails.

\section{ACKNOWLEDGEMENTS}

We thank Sayuri Gyotoku for help in conducting the experiment. Thanks are also due to members of KONARC and Nara Women's University for useful discussions and assistance, and 
to two anonymous reviewers for constructive criticism.

\section{REFERENCES}

Burky, A. J., J. Pacheco and E. Pereyra (1972) Temperature, water, and respiratory regimes of an amphibious snail, Pomacea urceus (Müller), from the Velezuelan savannah. Biol. Bull. 143: 304-316.

Carlsson, N. O. L., C. Bronmark and L.-A. Hansson (2004) Invading herbivory: the golden apple snail alters ecosystem functioning in Asian wetlands. Ecology 85: $1575-1580$.

Cowie, R. H. (2002) Apple snails as agricultural pests: their biology, impacts, and management. In Molluscs as Crop Pests (G. M. Baker ed.). CABI, Wallingford, pp. 145-192.

Darby, P. C., P. L. Valentine-Darby and H. F. Percival (2003) Dry season survival in a Florida apple snail (Pomacea paludosa Say) population. Malacologia 45: 179-184.

Fan, P. C., C. C. Wu, C. W. Yen and P. Huang (2000) Survival of Pomacea species out of water kept in $25^{\circ} \mathrm{C}$ laboratory condition. Bulletin of Malacology, Taiwan, ROC 24: $1-6$.

Lach, L., D. K. Britton, R. J. Rundell and R. H. Cowie (2000) Food preference and reproductive plasticity in an invasive freshwater snail. Biol. Invasions 2: 279-288.

Little, C. (1968) Aestivation and ionic regulation in two species of Pomacea (Gastropoda: Prosobranchia). $J$. Exp. Biol. 48: 569-585.

Lowe, S., M. Browne, S. Boudjelas and M. De Poorter (2000) 100 of the World's Worst Invasive Alien Species. The Invasive Species Specialist Group, IUCN, Auckland. 12 pp. (available online at: http://www.issg.org/).

Ozawa, A. and T. Makino (1988) Overwintering of the apple snail, Pomacea canaliculata (Lamarck), in Shizuoka Prefecture. Bull. Shizuoka Agric. Exp. Sta. 33: 65-77 (in Japanese with English summary).

R Development Core Team (2005) R: A Language and Environment for Statistical Computing. Version 2.2.1. R Foundation for Statistical Computing, Vienna (available online at: http://www.R-project.org/).

Shobu, S. (1996) Biology of apple snail, Pomacea canaliculata (Lamark), and its control. Plant Plot. 50: 211-217 (in Japanese).

Shobu, S., H. Mikuriya, J. Yamaguchi, M. Matsuzaki, S. Zen and T. Wada (2001) Estimating the overwintering mortality of the apple snail, Pomacea canaliculata (Lamarck) (Gastropoda: Ampullariidae) in a paddy filed of southern Japan using temperature data. Jpn. J. Appl. Entomol. Zool. 45: 203-207 (in Japanese with English summary).

Takahashi, K., H. Nishida and M. Seki (2000) Damage of the apple snail, Pomacea canaliculata, in paddy fields, and decreasing density of the snail by rotary cultivator. Nogyo-gijyutsu 55: 226-229 (in Japanese).

Takahashi, K., M. Seki, S. Higashi and T. Miike (2005) Development of technology by rotary tiller to control the density of apple snail. Nogyo-kikai-gakkaiho 67: 68-74 (in Japanese with English summary).

Tanaka, K., T. Watanabe, H. Higuchi, K. Miyamoto, Y. Yusa, T. Kiyonaga, H. Kiyota, Y. Suzuki and T. Wada (1999) Density-dependent growth and reproduction of the apple snail, Pomacea canaliculata: a density manipulation experiment in a paddy field. Res. Popul. Ecol. 41: 253-262.

The Ecological Society of Japan (ed.) (2002) Handbook of Alien Species in Japan. Chijin-shokan, Tokyo. 390 pp.

Wada, T. (1997) Ecology and management of the apple snail, Pomacea canaliculata. Nogyo-gijyutsu 52: 504-507 (in Japanese).

Wada, T., K. Ichinose, Y. Yusa and N. Sugiura (2004) Decrease in density of the apple snail Pomacea canaliculata (Lamarck) (Gastropoda: Ampullariidae) in paddy fields after crop rotation with soybean, and its population growth during the crop season. Appl. Entomol. Zool. 39: $367-372$.

Wada, T. and K. Yoshida (2000) Burrowing by the apple snail, Pomacea canaliculata (Lamarck); daily periodicity and factors affecting burrowing. Kyushu Plant Prot. Res. 46: 88-93 (in Japanese with English summary).

Watanabe, T., K. Tanaka, H. Higuchi, K. Miyamoto, T. Kiyonaga, H. Kiyota, Y. Suzuki and T. Wada (2000) Emergence of the apple snail, Pomacea canaliculata (Gastropoda: Ampullariidae), after irrigation in a paddy. Appl. Entomol. Zool. 35: 75-79.

Wilson, K. and I. C. W. Hardy (2002) Statistical analysis of sex ratio: an introduction. In Sex Ratios: Concepts and Research Methods (I. C. W. Hardy ed.). Cambridge University Press, Cambridge, pp. 48-92. 